Portland State University

PDXScholar

$11-2-1994$

\title{
The Relationship Between Intelligibility and Length and Complexity of Language in a Group of 4- and 5-Year-Old Children
}

Susan Fodell

Portland State University

Follow this and additional works at: https://pdxscholar.library.pdx.edu/open_access_etds

Part of the Speech and Rhetorical Studies Commons

Let us know how access to this document benefits you.

\section{Recommended Citation}

Fodell, Susan, "The Relationship Between Intelligibility and Length and Complexity of Language in a Group of 4- and 5-Year-Old Children" (1994). Dissertations and Theses. Paper 4746.

https://doi.org/10.15760/etd.6630

This Thesis is brought to you for free and open access. It has been accepted for inclusion in Dissertations and Theses by an authorized administrator of PDXScholar. Please contact us if we can make this document more accessible: pdxscholar@pdx.edu. 
The abstract and thesis of Susan Fodell for the Master of Science in speech Communication: Speech and Hearing Science were presented November 2, 1994, and accepted by the thesis committee and the department.

COMMITTEE APPROVALS:
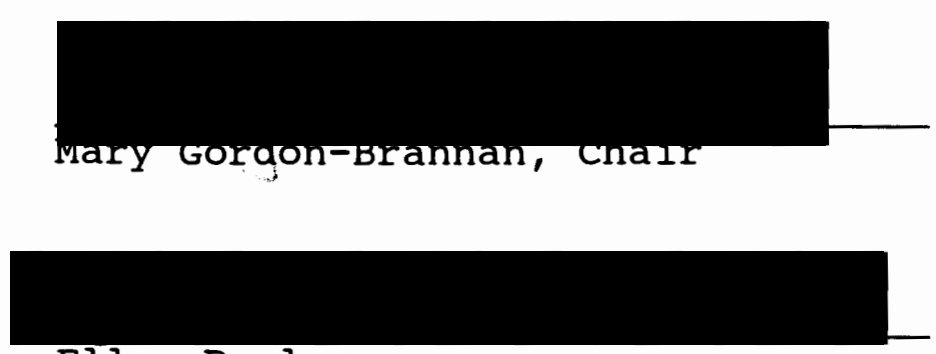

Ellen Reuler

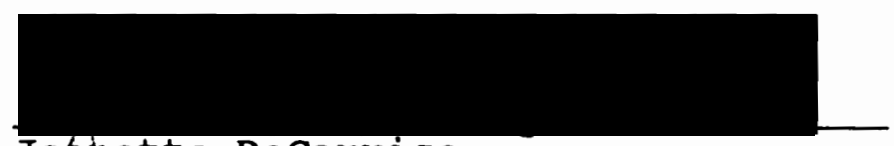

Jeanette DeCarrico

Representative of the office of Graduate studies

DEPARTMENT APPROVAL:

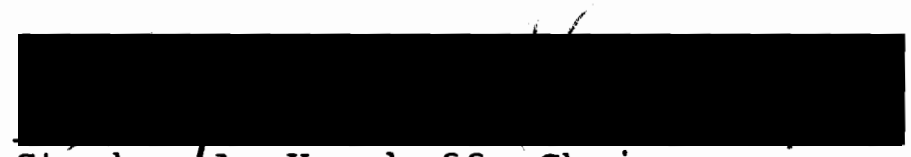

Stephan'A. Kosokoff, Chair

Department of Speech Communication

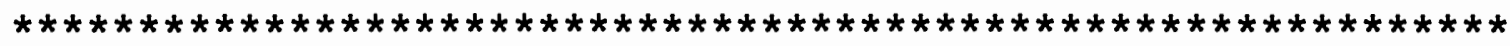

ACCEPTED FOR PORTLAND STATE UNIVERSITY BY THE LIBRARY

by

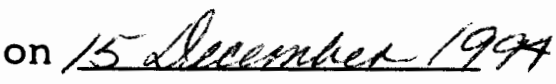


ABSTRACT

An abstract of the thesis of Susan Fodell for the Master of Science in speech Communication: Speech and Hearing Sciences presented November 2, 1994.

Title: The Relationship Between Intelligibility and Length and Complexity of Language in a Group of 4- and 5-Year-old children.

Previous research has indicated that speech and linguistic variables develop concurrently. When one aspect of speech and linguistic development is delayed, there are typically associated delays in another area as well. This interactive relationship has been studied extensively in the context of phonological and syntactical development, as well as fluency and syntactical development. The relationship between intelligibility and linguistic proficiency has not been studied as extensively.

The purpose of this study was to examine the relationship between varying levels of intelligibility and length and complexity of language in preschool-aged children. Mean length of utterance was correlated with the mean percentage of intelligible words in a continuous speech sample.

The following questions were addressed: 
1. Does a significant positive correlation exist between MLU and percentage of intelligible words in a continuous speech sample?

2. Are there significant differences in the correlations of MLU and percentage of intelligible words between four groups of young children with a range of intelligibility levels: mild, mild-moderate, moderatesevere, and severe?

A continuous speech sample was collected from each of the subjects. Children were separated into four groups based on intelligibility ratings of mild, mild-moderate, moderate-severe, and severe. These ratings were based on the percentage of mean intelligible words in a continuous speech sample. Correlations between mean length of utterance (MLU) and the percentage of intelligible words (PIW) were obtained using the Pearson Product Moment Correlation. Regression analysis was used to determine whether a significant difference exists between the correlations for the four groups of intelligibility.

An overall significant positive correlation was found between MLU and PIW when the four groups of subjects were combined. Significant correlations were also found between MLU and PIW for the groups with intelligibility ratings of mild and mild-moderate. No significant correlations were revealed between the two variables for the moderate-severe or severe groups. Regression analysis indicated no 
significant differences in the correlations for the four groups of intelligibility. This resulted in a failure to reject the null hypothesis that the correlations among the four groups of intelligibility levels will be the same. 


\section{THE RELATIONSHIP BETWEEN INTELLIGIBILITY AND LENGTH AND COMPLEXITY OF LANGUAGE IN A GROUP OF 4- AND 5-YEAR-OLD CHILDREN}

by

SUSAN FODELL

A thesis submitted in partial fulfillment of requirements for the degree of

Master of Science in Speech Communication:

Speech and Hearing sciences

Portland State University 1994 
ACKNOWLEDGEMENTS

Foremost, I would like to extend my thanks and gratitude to Dr. Mary Gordon-Brannan for all of her efforts and support. She has helped me immensely not only with this project but she has also been supportive throughout my graduate career. I could not have completed either endeavor without her support. I will remember all 48 versions of The Relatives came for years to come. I would also like to thank my committee members, Ellen Reuler and Jeanette Decarrico, for their time and input. Their suggestions and time were greatly appreciated. Thanks also goes to Gene Enneking for all of his statistical advice.

Special thanks to my friends and family for their support and encouragement over the past two years. I would like to thank Joe for his patience and computer expertise. He has been a wonderful friend and I could never thank him enough. Thanks to Ginny for a lifetime of encouragement. I would also like to thank Heidi for making me go to Las Vegas instead of reading this thesis one more time. 
TABLE OF CONTENTS

PAGE

ACKNOWLEDGMENTS . . . . . . . . . . . . . . . ii

LIST OF TABLES . . . . . . . . . . . . . . . v v

CHAPTER

I INTRODUCTION AND STATEMENT OF PURPOSE . . . . 1

Introduction . . . . . . . . . . . . 1

Statement of Purpose . . . . . . . . 3

Definition of Terms . . . . . . . . 5

II REVIEW OF THE LITERATURE . . . . . . . . . 7

Language Analysis Procedures . . . . . 7

Elicited Imitation

Continuous Speech Samples

Relationship Between Intelligibility

and Development of Language . . . . . 16

III METHOD . . . . . . . . . . . . . . . 18

Subject Description . . . . . . . . 18

Procedure .............. . 19

Scoring

Procedures for the Present Study

Reliability

Statistical Analysis . . . . . . . . 23

IV RESULTS AND DISCUSSION . . . . . . . . . . 24

Results . . . . . . . . . . . . 24

Correlation Between MLU and PIW

Significant Differences Between Correlations

Discussion . . . . . . . . . . 27

V SUMMARY AND IMPLICATIONS . . . . . . . . 33 


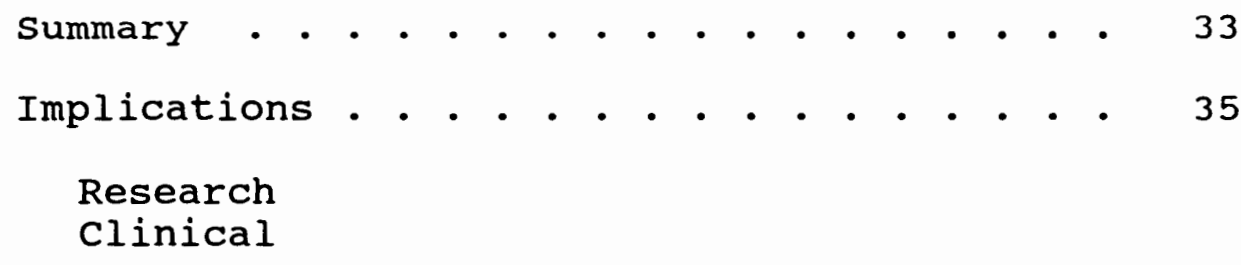

REFERENCES . . . . . . . . . . . . . . . . . . . 37

APPENDIX

A. Individual Subject Data . . . . . . . . . . . 41

B. Utterance Examples of the Four

Intelligibility Groups . . . . . . . . . 43 


\section{LIST OF TABLES}

TABLE

PAGE

1 Pearson Product Moment Correlations ( $\underline{\mathbf{r}}$ )

and Significance Levels Between Mean

Length of Utterance (MLU) and

Percentage of Intelligible Words (PIW)

for Four Levels of Intelligibility . . . . 25

2 F Values ( $\underline{F}$ ) and Significance Levels ( $\mathrm{Q}-$

value) for Testing Whether or not Two

Correlations are Equal . . . . . . . . 27 
CHAPTER I

INTRODUCTION AND STATEMENT OF PURPOSE

Introduction

Speech and linguistic variables develop simultaneously in children. Children with phonological delays typically exhibit delays in expressive language abilities. The interactive relationship between phonology and syntax has been well examined; however, the relationship between intelligibility and linguistic development has not been studied as extensively. Intelligibility of speech is commonly associated with the use of phonological processes. Intelligibility may be equally affected by expressive language delays. When continuous speech samples are analyzed, it is possible to determine the percentage of intelligible words as well as length and complexity of language.

Development of syntax and morphology in the preschool years is dependent on the child's ability to produce phonological units (Owens, 1992). The interaction between linguistic variables and phonology has been investigated by several researchers (Panagos \& Prelock, 1982; Paul \& Shriberg, 1982; Weston \& Shriberg, 1992). These studies have revealed that children with phonological delays are likely to become less intelligible as syntactic complexity increases (Panagos, Quine, \& Klich, 1979; Prelock \& Panagos, 1989). Similarly, simplification of syntax is likely to 
occur in children with delayed phonology (Panagos \& Prelock, 1982; Paul \& Shriberg, 1982). Reductions in fluency also occur in some children as the length and complexity of an utterance increases (Gaines, Runyan, \& Meyers, 1991). Additionally, children with profound developmental language delays have been shown to produce more dysfluent speech than their same-aged peers (Hall, Yamashita, \& Aram, 1993). When the linguistic or phonetic demands of an utterance exceed the child's capacities to produce it, simplification of the structures or reductions in fluency are likely to occur. A child with reduced intelligibility may not only decrease the demands of the phonological structure; he or she may also simplify the linguistic structure. An underlying general encoding deficit may result in simplifications in syntax and phonology, as well as reductions in fluency.

The extent to which speech and language variables are affected may indicate the level of unintelligibility. Gordon-Brannan (1993) found a significant correlation between percentage of intelligible words in connected speech and phonological deviancy. Phonological processes are rules used by children to simplify adult forms of speech. These processes are used by normally developing children until the age of 4 , with the majority of processes no longer being used after that time (Shriberg \& Kwiatkowski, 1980). Children are typically intelligible to people outside their immediate social environment when they reach the age of 4 
(Grunwell, 1992). Children with phonological delays extend their use of phonological processes beyond the normal developmental period and may also produce nondevelopmental phonological processes (Weiss, Gordon, \& Lillywhite, 1987), thus extending unintelligible speech into the preschool period.

The extent of unintelligibility may be related, not only to the level of phonological deviancy, but also to the extent the linguistic code is simplified. A child in the preschool period uses increasingly complex sentence forms. By the age of 5 , a child has $90 \%$ grammar acquisition (Owens, 1992). The degree to which a child is intelligible may also reflect mastery of the linguistic system.

Phonology and syntactic skill have been shown to develop concurrently in children. Additionally, a strong correlation between phonological deviancy and intelligibility of speech has been shown to exist; however, the relationship between intelligibility and development of language has not been studied extensively. This study examined the relationship between varying levels of intelligibility and length and complexity of language.

statement of Purpose

The purpose of this study was to examine the relationship between the level of intelligibility and length and complexity of language in preschool-aged children. Specifically, Mean Length of Utterance (MLU) was correlated 
with the mean percentage of intelligible words (PIW) in continuous speech samples. The study sought to answer the following questions:

1. Does a significant positive correlation exist between MLU and mean percentage of intelligible words in a continuous speech sample?

2. Are there significant differences in the correlations of MLU and mean percentage of intelligible words among four groups of young children with a range of intelligibility levels: mild, mild-moderate, moderatesevere, and severe.

The first research hypothesis tested in this study is: MLU has a significant positive correlation with intelligibility in continuous speech samples. It was expected that decreases in intelligibility of children will be related to decreases in the length and complexity of language. The corresponding null hypothesis is that MLU does not have a significant positive correlation with intelligibility in a continuous speech sample. The second research hypothesis is: The correlations among the four groups of intelligibility levels will be significantly different. It was expected that a significantly stronger positive correlation between MLU and intelligibility exists as intelligibility decreases. Alternatively, the null hypothesis is that correlations among the four groups of intelligibility levels are the same. 


\section{Definition of Terms}

For the purpose of this study, the following definitions were used:

Disfluent: The nonfluent speech of people who do not stutter; the nonstuttered, nonfluent speech of people who do stutter (Ham, 1990).

Dysfluent: The stuttered speech of stutterers; the stuttered speech of people who do not usually stutter (Ham, 1990)

Expressive language delay: Children who at 24-34 months were classified as late talkers and at 4 years of age scored below the 10 th percentile on the Developmental Sentence score (DSS) (Lee, 1974).

History of expressive language delay: Children who at 24-34 months were classified as late talkers and at 4 years of age scored at the 10th percentile or higher on the DSS (Lee, 1974).

Intelligibility: The degree to which a person's speech is understood by a listener (Gordon-Brannan, 1993).

Late talker: Children who produced less than 50 different words or no two-word combinations at age 20-34 months based on a parent report, the Language Development Survey (Rescorla, 1989).

Mean Length of Utterance (MLU): Mean number of morphemes per utterance in a speech sample (Brown, 1973)

Morpheme: The smallest unit of meaning in a language. 
Phonological processes: A regularly occurring speech

sound pattern in an individual's utterances, usually one that simplifies an adult phonological pattern (Hodson \& Paden, 1991). 
CHAPTER II

REVIEW OF THE LITERATURE

Children who experience a delay in one area of linguistic development are often affected in another area as well. Research has shown this relationship to exist not only between linguistic complexity and phonology, but also between linguistic complexity and fluency. Reductions in fluency, phonological proficiency, and linguistic complexity of a message may be due to a limited capacity to encode the linguistic material. A review of the literature regarding the relationship among phonology, fluency, intelligibility, and language development through the preschool period follows.

\section{Language Analysis Procedures}

Elicited imitation tasks, as well as analysis of continuous speech samples, have been used to assess the interactive effects among fluency, phonology, and language. Researchers have used elicited imitation to determine what effect increased syntactic complexity and length of an utterance have on a child's ability to encode the message. These elicited imitation tasks require the child to imitate a range of earlier- and later- developing linguistic structures. Connell \& Myles-zitzer (1982) found that linguistic errors made on elicited imitation tasks may or may not accurately reflect a child's linguistic competence. In contrast, continuous speech samples can be used to assess 
phonological and linguistic variables at the child's own level of production. Studies reviewed will be separated into those using elicited imitation tasks and continuous speech samples.

\section{Elicited Imitation}

Panagos et al. (1979) sought to determine what effect increasing levels of grammatical complexity have on articulatory performance. Seventeen children with phonological delays who participated in the study were required to repeat noun phrases and declarative and passive sentence constructions that contained either mono- or disyllable words. Results indicated that when later developing consonants $\left(\theta, d z, \int, f f\right)$ occurred in complex words and syntactically complex structures, phonological processes were used with greater frequency. The investigators suggested children with phonological disorders have an underlying limitation in organizational ability. According to their model, linguistic expression is organized into a hierarchical arrangement of complexity. Syntactic, morphological, and phonological elements interact and control phonetic behavior. Competing performance in other Iinguistic areas thus reduces the ability to organize phonetic behavior and results in simplified phonology.

Panagos and Prelock (1982) provided further support for the hypothesis of the interrelatedness of syntactic and phonological abilities. The purpose of their study was to 
determine if phonological structure influences children's syntactic processing. They hypothesized that syntactic performance would be deficient when complex phonological constructions were utilized in an elicited imitation task. Results indicated simplification of syntactic patterns occurred as phonological complexity increased. These results were interpreted in a similar manner as the results of the Panagos et al. (1979) study. Researchers concluded that syntactic patterns were simplified due to a limited processing capacity.

Elicited imitation, as well as a sentence creation task, were used in a later Prelock and Panagos (1989) study to examine the effects of linguistic complexity on phonological production. They also sought to determine if complexity effects were as apparent in production tasks as they were in repetition tasks. The 60 subjects who participated in the study were separated into four groups based on expressive speech and language abilities as well as age. As syntactic and phonological complexity increased, children with language disorders made significantly more simplification errors on both tasks than the other groups. The effects of complexity, however, were less pronounced in the sentence production task than in the elicited imitation task. Lexical omissions, followed by lexical substitutions and use of phonological processes represented the three greatest proportions of simplification errors. These 
results support the previous findings of a limited encoding capacity (Panagos \& Prelock, 1982; Panagos et al., 1979). Researchers found that children interchange the complexity of syntax, phonology, and lexical items during the moment of speech. When the demands of an utterance exceed the child's capacity to produce it, trade-offs are made to preserve meaningful expression. These trade-offs interfere with children's intelligibility and syntactic accuracy.

Trade-offs between linguistic expression and fluency are also apparent during tasks with increased complexity and length. McLaughlin and Cullinan (1989) studied linguistic factors and length as they contribute to dysfluencies in children who were nonstutterers. Ten female and male 5year-olds with no history of communication disorders participated in the study. The purpose of the study was to elicit language dysfluencies under naturalistic conditions and with tasks in which length and complexity were manipulated. Dysfluencies were characterized by part-word repetitions, whole-word repetitions, dysrhythmic phonations, and tense pauses. Investigators found that the relationship between utterance length and complexity versus total dysfluencies was not significant in the spontaneous speech tasks. Subjects, however, exhibited increased dysfluencies as length and complexity increased in the modeling task. Additionally, levels of dysfluency in the language sample and modeling tasks were significantly correlated for 
subjects as a whole. Because of the increased stuttering dysfluencies during modeling tasks of increased linguistic complexity, difficulty in learning the linguistic code may be a contributing factor in the development of stuttering. These results may be interpreted in a similar manner to the Panagos and Prelock (1982) study. Compromises in both phonology and fluency occur when the linguistic demands become too great.

\section{Continuous speech Samples}

The characteristics of 114 children with phonologic disorders of unknown origin were investigated by shriberg, Kwiatkowski, Best, Hengst, and Terselic-Weber (1986). Analyses were based on continuous speech samples and case history data. Researchers found significant cognitive and linguistic deficits for one third of the children. Seventyeight percent of the subjects had productive errors on pronouns, $66 \%$ had delayed syntax, and $45 \%$ showed delayed onset of speech. Additionally, $30 \%$ experienced lexical retrieval problems, and $22 \%$ had language formulation problems.

Amorosa, von Benda, and Wagner (1990) conducted a longitudinal study on 18 preschool and school-age children who were unintelligible. Seventeen of the subjects displayed deficits in grammar during a spontaneous speech sample. A strong relationship was found between the cognitive measures of nonverbal IQ, comprehension, and 
visual sequential memory and eventual outcome of grammatic skills. Children with above average IQs had a higher positive eventual outcome than those children with low-toaverage intelligence quotients.

Miller (1991) found a relationship between normal and delayed language development and percentage of intelligible words. Subjects were classified as either normal, expressive language delayed, or late talkers. Mean age of the subjects was 50 months. Children who were late talkers or expressively language delayed had significantly more unintelligible words than normally developing children.

The phonological behavior of normally speaking and language disordered children was investigated by Schwartz, Leonard, Folger, and Wilcox (1980). Six subjects with a mean age of $3: 1$ participated in the study with three children each in the language disordered group and the normal group. They were matched on the basis of MLU and sex. A spontaneous speech sample was collected and analyzed for the use of phonological processes. No significant differences were found between the groups on the basis of quantity or type of phonological processes used. The authors suggested that phonology and linguistic behavior may be closely related in the early stages of language development. However, as the complexity of a child's syntax increases, phonological development may lag behind. 
Conversely, phonological production did show an interaction with syntax and morphology in children with speech delays in Paul and Shriberg's (1982) study. The continuous speech samples of 30 children with speech delays were analyzed. The children were then categorized into four different groups on the basis of their speech and syntactic abilities. Eighty-six percent of the sample had delays in productive syntax; $66 \%$ percent of those subjects had concomitant syntactic and phonological deficits. The other $20 \%$ showed restricted use of morphological markers due to the occurrence of phonological simplifications. Fifty percent of this sample supported previous claims that limited encoding capacity is responsible for syntactic and phonological simplifications (Panagos et al., 1979; Panagos \& Prelock, 1982; Prelock \& Panagos, 1989). These children tended to simplify their syntactic and phonological productions when the demands of an utterance exceeded their capacities. The other half of the sample, however, was able to match the phonological structure to the level of syntactic complexity used in their utterances. Researchers concluded that a limited encoding capacity was not an adequate explanation for all children with developmental speech delays.

other researchers have looked at linguistic and contextual variables that may be associated with unintelligibility of preschool age children. Weston and 
Shriberg (1992) based their assumptions that intelligibility may be affected by these variables on the findings appearing in the fluency literature that dysfluencies increase in the presence of increased utterance length and syntactic complexity (Gaines et al., 1991; Hall et al., 1993). Analysis of continuous speech samples revealed that length had a significant effect on the intelligibility of an utterance; however, syntactic complexity did not show a significant effect on intelligibility. Although Weston and Shriberg (1992) used continuous speech samples in their study, only specific utterance types were analyzed for effects of complexity. These included simple sentences, simple sentences with object modifiers, and simple sentences with subject modifiers and/or true complex sentences. The authors hypothesized the complexity subgroups may have not significantly challenged the subjects.

Jartun (1992) sought to determine if there were significant differences in the intelligibility levels of children with normally developing language, a history of language delay, or an expressive language delay. Results indicated that children with normal language development had significantly higher intelligibility levels than subjects who had a history of language delay or were expressive language delayed. While, the children with a history of language delay had lower intelligibility levels, their syntactic development fell within the normal range. The 
researcher concluded that these results may be evidence to support the interrelatedness of intelligibility and linguistic development.

Reduction of processing demands has been explored, not only in the realm of phonology, but also in the fluency literature. Hall et al. (1993) studied the relationship between language and fluency in children with developmental language disorders. They hypothesized that children with developmental language disorders are at risk for dysfluent speech because they have difficulties with at least one aspect of speech and language. They sought to determine if children with developmental language disorders could be divided on the basis of frequency of dysfluencies. Another aspect of the study was to determine whether highly dysfluent children could be differentiated on the basis of language skills. The spontaneous language samples of 60 preschool children with developmental language disorders were analyzed.

These researchers found the subjects could be separated into two distinct groups based on the quantity of dysfluencies. They consisted of the highly dysfluent (HD) and normally dysfluent (ND) groups. Additionally, Hall et al. (1993) sought to determine whether the HD and ND groups could be further identified on the basis of language skill. It was found that language function could be used to identify the subjects as either highly dysfluent or normally 
dysfluent. Overall, individual cases grouped correctly by language function was $75 \%$. HD subjects had more significant impairments in morphosyntactic skills than the ND group. These data support the notion of an underlying encoding deficit that affects both fluency and linguistic expression. Reductions in fluency and simplifications of phonology both occur as the linguistic code becomes too demanding.

$$
\begin{gathered}
\text { Relationship Between Intelligibility } \\
\text { and Development of Language }
\end{gathered}
$$

Previous research has examined the relationship between phonology and syntax, as well as fluency and syntax. A variety of tasks and procedures have been used to assess the interaction that occurs when phonological and syntactic complexity are increased. Associations were found between simplification of phonology and syntax when elicited imitation procedures were used. Similar reductions in fluency were seen when these procedures were used; however, the validity of elicited imitation has been questioned as a predictor of language performance in children (Connell \& Myles-zitzer, 1982). Analyses of continuous speech samples have revealed similar interactions between phonological and syntactic skill, although the results were not as robust (Paul \& Shriberg, 1982). Continuous speech samples have also been used to examine the relationship between dysfluencies and linguistic complexity. Dysfluencies were produced with greater frequency in children with more 
profound developmental language delays than their same age peers.

Concomitant delays in syntactic ability have been shown to exist in children with phonological delays. Conversely, more unintelligible words were produced by late talkers and children with expressive language delay than children with normally developing language. Research indicates a relationship exists between length of utterance and intelligibility. Few studies have looked at the relationship between varying levels of intelligibility and complexity of language throughout an entire continuous speech sample. A limited encoding capacity theory has not been examined in the context of intelligibility. 
CHAPTER III

METHOD

Subject Description

The subjects for this study participated in GordonBrannan's (1993) doctoral research. They were recruited from preschools and speech-language pathology caseloads in the Portland, oregon, greater metropolitan area. Fortyeight children ranging in age from 4:0 to 5:6 (mean 4:7) participated in this study. Subjects included 20 females and 28 males.

The subjects had no known neurological, motor, or physical impairment that might affect speech production. No clinically significant laryngeal or resonance deviancies were noted at the time of testing. Forty-five subjects passed pure tone audiometric screening conducted at the frequencies of $500,1000,2000$, and $4000 \mathrm{~Hz}$ at $25 \mathrm{~dB} \mathrm{HL}$ bilaterally. Three subjects displayed mild hearing losses with pure tone averages of $35 \mathrm{~dB}$ or less bilaterally. The Test of Auditory Comprehension of Language-Revised (TACL-R) (Carrow-Woolfolk, 1985) was given to all subjects to assess receptive language skills. All subjects scored above the 10th percentile with the exception of one subject. This subject remained in the study as the investigator and the child's clinician judged that the test score was not representative of his functional receptive language skills. To ensure a broad range of phonological functioning 
levels, subjects were divided into four groups of phonological proficiency: (a) adult-like, (b) mildly deficient, (c) moderately deficient, and (d) severely deficient. Group placement was based on performance on the 1-Minute Measure of Homonomy and Intelligibility (Hodson, 1992) with 12 subjects being placed in each group.

\section{Procedure}

A continuous speech sample was collected from each subject while looking at pictures and a book. The mean percentage of intelligible words, as judged by four unfamiliar listeners, for each sample was calculated. For this study, the subjects were re-classified into four groups on the basis of mean percentage of intelligible words understood by unfamiliar listeners in a continuous speech sample. Subjects were divided into four groups of intelligibility: mild, mild-moderate, moderate-severe, and severe. Because, a severity rating measure for the percentage of intelligible words in a continuous speech sample has not yet been devised, the severity ratings used for the purposes of this study paralleled the levels derived for the percentage of consonants correct (PCC) procedure (Shriberg \& Kwiatkowski, 1982). The percentage distinctions were assigned as follows: $85-100 \%, \operatorname{mild} ; 65-85 \%$, mildmoderate; $50-65 \%$, moderate-severe; and less than $50 \%$ severe. The continuous speech samples were used to determine an index of the structural development of language by 
calculating the Mean Length of Utterance (MLU) for each sample.

In order to obtain the continuous speech sample, each subject was first asked open-ended questions and requests (e.g., "Who is in your family?", "Tell me about your family", and "Tell me about your pets") as a warm-up. Subjects then looked at five pictures of children engaged in everyday activities and a child's book, The Relatives came (Rylant \& Gammel, 1985) to elicit the speech sample. The investigator and speaker were seated across from each other at a table. A microphone, placed on foam or in a microphone stand, was approximately 6" from the subject's mouth. The child's parent or caregiver was allowed to stay in the room during the speech sample. The continuous speech samples were audio and video taped. A Panasonic camcorder, VHS Reporter, Ag-100, and a Sharp SX D200 digital audiotape recorder, in conjunction with an AKG, Model C451, capacitor flat microphone was used for the recordings.

A 100-word sample was selected from a segment of the speech sample obtained while looking at the book. If fewer than 100 words were uttered, the sample also included utterances elicited by the pictures. Words that were immediate repetitions of the investigator, interjections and filler words (e.g., "oh"), "no" (and other words connoting "no" e.g., "nope" and "naw"), and "yeah" (and other similar 
words, e.g., "yup" and "yep") also were not included in the scored sample.

The continuous speech samples were transcribed orthographically by research assistants and the investigator. Initial transcriptions were verified by the investigator. The transcripts of children who were in the moderately and severely deficient groups were verified by a parent or caregiver and the investigator through the use of video or audiotape. These transcripts served as the key for scoring percentage of intelligible words.

\section{Scoring}

The percentage of intelligible words was determined from orthographic transcriptions of four speech-language pathology graduate students in the Portland state University Speech and Hearing Sciences Program who had completed coursework in phonology and also had some clinical experience working with phonological disorders. Listeners individually orthographically transcribed the continuous speech samples. Each utterance was listened to a maximum of three times. This was done in their own homes with their personal analogue audiotape recorders. The listeners' transcripts were compared to the key transcripts. The percentage of words correctly understood by each listener were computed for each speaker. The mean percentage of words correctly understood by the listeners was computed for each of the continuous speech samples. 


\section{Procedures for the Present study}

MLU was calculated for a 50-utterance segment of each continuous speech sample. The 50-utterance sample included the 100-word sample used to determine the percentage of intelligible words. The sample also included additional utterances elicited by the book if fewer than 50 utterances were said. Utterances were segmented on the basis of rising or falling terminal intonation contours. MLU was calculated according to the procedures described by Miller (1981) with one exception: an inflection that was expressed unconventionally due to phonological errors was counted as a morpheme if there were two consistent productions of the form.

Reliability

Inter- and intrarater reliability were determined with the Pearson product moment (Pearson $\underline{r}$ ) correlation for $15 \%$ of the MLUs calculated. Inter- and intrarater reliability were both determined to be .99. These figures represent a high level of agreement. Intrarater reliability was not calculated for the percentage of intelligible words as the listeners were allowed to listen to each sample up to three times. Interrater reliability was calculated with Pearson $\underline{\underline{r}}$ correlations for the percentage of words understood in the continuous speech sample. The correlation coefficients ranged from .86 to .95 for the six pairs of listeners. 
Statistical Analysis

The Pearson $\underline{r}$ was used to calculate the correlation between the two variables: (a) percentage of intelligible words and (b) MLU, both determined from continuous speech samples. Regression analysis was used to determine if a significant difference exists between the correlations of the four groups of subjects. The slope of the line of best fit was used as a basis for this test. An F-test was then performed to compare the slopes of two lines. Statistical significance was set at a .05 alpha level $(\underline{p}<.05)$. 
CHAPTER IV

\section{RESULTS AND DISCUSSION}

Results

The questions asked in this study were intended to determine if there is a significant positive correlation between percentage of intelligible words in a continuous speech sample and MLU, and if there is a significant difference in the correlations for the four groups of intelligibility. The specific questions asked were: (a) Does a significant positive correlation exist between MLU and percentage of intelligible words in a continuous speech sample? (b) Are there significant differences in the correlations of MLU and percentage of intelligible words between the four groups of young children with a range of intelligibility levels: mild, mild-moderate, moderatesevere, and severe.

Correlation Between MLU and PIW

Pearson $\underline{r}$ correlations were computed to determine if there was a correlation between MLU and mean percentage of intelligible words (PIW). To determine if a significant correlation $(p<.05)$ exists between the variables, a onetailed $\underline{t}$-test was calculated. Results of the Pearson $\underline{r}$ and the significance level (p-values) are shown in Table 1. The correlation between MLU and PIW was . 644 when the four groups of subjects were combined, which represents a moderate to high relationship. Thus, the more intelligible 
the speech, the higher the MLU. The correlation values between MLU and PIW for the mild and mild-moderate groups were .467 and .591 , respectively, which represent a relationship of moderate strength. Significant correlations were not found for the moderate-severe and severe groups. However, the $\underline{\underline{r}}$ value for the severe group approached significance (see Table 1).

Table 1

Pearson Product Moment Correlations (r) and Significance Levels Between Mean Length of Utterance (MLU) and Percentage of Intelligible Words (PIW) for Four Levels of Intelligibility

\begin{tabular}{lll} 
Group & $\underline{r}$ & Significance Level \\
\hline $\begin{array}{l}\text { Group I } \\
\text { Mild }\end{array}$ & .467 & .0250 \\
$\begin{array}{l}\text { Group II } \\
\text { Mild-Moderate }\end{array}$ & .591 & .0250 \\
$\begin{array}{l}\text { Group III } \\
\text { Moderate-Severe }\end{array}$ & -.120 & NS \\
$\begin{array}{l}\text { Group IV } \\
\text { Severe } \\
\text { Combined Groups }\end{array}$ & .629 & .1000 \\
\hline
\end{tabular}

Additionally, the coefficient of determination $\left(\underline{\underline{r}}^{2}\right)$ was calculated to determine the percentage of shared variance between the variables MLU and PIW. Shared variance reflects 
between the variables MLU and PIW. Shared variance reflects the percentage of aspects common to the two variables being correlated. The percentages of shared variance between MLU and PIW for the various groupings were as follows: (a) combined groups shared $41 \%$, (b) the mild group shared $22 \%$, (c) the mild-moderate group shared $35 \%$, (d) the moderatesevere group shared $1.4 \%$, and (e) the severe group shared $40 \%$

\section{Significant Differences Between Correlations}

Regression analysis was used to determine if significant differences exist between the correlations of the four intelligibility groups. The slope of the line of best fit was used as a basis for the comparison and an $F$ test was then conducted. The $\underline{F}$ test is a result of the regression process which compares the slopes of two lines (Gene Enneking, personal communication, August 11, 1994). significance was set at the .05 level of confidence. The null hypothesis was not rejected as no significant differences between the slopes existed. See Table 2 for results of the $\underline{F}$ test. These results seem to indicate that there is not a stronger or weaker correlation between MLU and PIW as intelligibility decreases. There may not have been enough data points in the moderate-severe and severe groups to support the hypothesis. These groups each contain 6 data points, while the mild and mild-moderate groups contain 22 and 14 , respectively. 
Table 2

F Values (F) and Significance Levels (p-value) for Testing Whether or not Two Correlations are Equal

\begin{tabular}{|c|c|c|c|c|c|c|c|}
\hline $\begin{array}{l}\text { Group } \\
\text { pairs }\end{array}$ & 1 & 2 & & 3 & & 4 & \\
\hline 1 & -- & $\begin{array}{l}\underline{F}= \\
\underline{p}=\end{array}$ & $\begin{array}{l}.27 \\
.6069\end{array}$ & $\begin{array}{l}\underline{F}= \\
\underline{p}=\end{array}$ & $\begin{array}{l}2.05 \\
.1651\end{array}$ & $\frac{F}{p}$ & $\begin{array}{l}=1.24 \\
=.2765\end{array}$ \\
\hline 2 & -- & -- & & $\begin{array}{l}\underline{F}= \\
\underline{p}=\end{array}$ & $\begin{array}{l}1.95 \\
.187\end{array}$ & & $\begin{array}{l}=.67 \\
=.4251\end{array}$ \\
\hline 3 & -- & -- & & -- & & & $\begin{array}{l}=.68 \\
=.4335\end{array}$ \\
\hline
\end{tabular}

Discussion

The purpose of this study was to examine the relationship between varying levels of intelligibility and length and complexity of language in preschool-aged children. This information would add to the base of knowledge concerning the relationship between phonological and syntactic skills. Further investigation of intelligibility may reveal it can be used as a predictive measure of language abilities.

MLU was correlated with PIW of a continuous speech sample. Also, this study examined whether there was a significant difference between the correlations for the four groups of intelligibility. The subjects in this study were separated into four groups based on the percentage of mean intelligible words in a continuous speech sample. The 
percentage distinctions are: 85-100\%, mild; 65-85\%, mildmoderate; 50-65\%, moderate-severe; and less than 50\%, severe.

The results of this study indicated a significant positive correlation between MLU and PIW when the four groups of subjects were combined. Additionally, results indicated significant positive correlations between MLU and PIW for the mild and mild-moderate groups. Significant correlations were not found for the moderate-severe and severe groups, although the correlation for the severe group approached significance. The lack of a significant correlation between Iinguistic complexity and intelligibility at these levels suggests independent development of intelligible speech and linguistic expression at lower intelligibility levels. However, as mentioned previously, there may not have been enough data points in these groupings to detect a correlation.

These results do suggest an overall positive relationship between the variables of intelligibility and linguistic proficiency. Thus, as intelligibility decreases, the length and complexity of a child's language decreases as well. It appears from the results of the current study that children with decreased MLU scores are more likely to delete auxiliary and copular verb forms and use a shorter utterance length than subjects with higher MLU scores. Additionally, the subjects with reduced intelligibility used phonological 
processes with greater frequency. These aspects of the subjects' linguistic systems seem to contribute to the overall positive relationship between the variables investigated. Conversely, as intelligibility increases, linguistic proficiency may increase as well. Research by (Panagos, et al., 1978; Panagos \& Prelock, 1982; Paul \& Shriberg 1982, and Prelock and Panagos 1989) attained results similar to the present study. Their studies indicated phonologically delayed children have concomitant delays in syntax. The results of the current study also suggest that reduced intelligibility may be associated with language delays. Conversely, Jartun (1992) found that both the history of language delay and the expressive language delay groups had significantly lower intelligibility levels than the group with normal language development. Panagos et al. (1979), Panagos \& Prelock (1982), Paul \& Shriberg (1982), McLaughlin \& Cullinan (1989), Prelock \& Panagos (1989), and Hall et al. (1993) suggested a limited encoding factor could in part explain the results of their studies. The results of this study could be interpreted in a similar manner. These studies suggest that a limited capacity to encode information may result in systematic reductions of fluency, phonological structure, and linguistic complexity. The significant relationship between MLU and PIW, when the four groups of subjects are combined, seems to indicate an underlying encoding deficit may, in 
part, explain the results of this study. As a child's capacity to encode information decreases, a reduction in linguistic complexity and intelligibility subsequently occurs in order to reduce processing demands.

Paul \& Shriberg (1982) found that $50 \%$ of their sample supported a limited encoding capacity theory. However, $50 \%$ of the sample was actually able to increase the proficiency of their phonological production to meet the linguistic demands of the utterance. In the present study, $41 \%$ percent of the variance between MLU and PIW could be accounted for when the groups of subjects were combined. Because a large portion of the variance between MLU and PIW could not be accounted for, it is possible that a portion of the subjects in the current study may actually be able to increase their intelligibility to meet the linguistic demands of the utterance. Additional studies may reveal findings similar to Paul \& Shriberg (1982).

Previous research has revealed less pronounced linguistic affects during naturalistic production tasks than during elicited imitation tasks (McLaughlin \& Cullinan, 1989; Prelock \& Panagos, 1989). The results of the present study seem to support the previous findings which show less pronounced effects during naturalistic tasks. Perhaps more pronounced effects would have been noted if the subjects had performed an elicited imitation task rather than spontaneous speech samples. The validity of these tasks as tools to 
assess linguistic proficiency, however, has been questioned (Connell \& Myles-zitzer, 1982).

Possibly the MLU is not sensitive enough to measure the linguistic skills of children at the age level investigated in this study. Alternative assessment measures include Developmental Sentence Scoring (DSS) (Lee, 1974), the Index of Productive Syntax (IPSyn) (Scarborough, 1990), and Assigning Structural Stage (ASS) (Miller, 1981).

Weston \& Shriberg (1992) found that length, and not linguistic complexity, had a significant effect on the intelligibility of portions of continuous speech samples. MLU is affected by the length and complexity of an utterance and thus the present study indicates length as well as complexity may have a relationship with the intelligibility of an utterance. It is not known to what extent the separate variables of length and complexity contributed to the level of intelligibility. Therefore, additional research could be carried out to determine the separate effects of length and complexity when a complete continuous speech sample is analyzed.

A stronger relationship between language development and lower levels of intelligibility may have been found if a more stratified age sample had been used. Schwartz et al., (1980) found that children with normally developing language and language delays did not exhibit significant differences when compared on the basis of quantity and type of 
phonological processes used. The mean age of the subjects was $3: 1$. These researchers concluded that phonology and linguistic behavior may be closely related in the early stages of language development. However, as the complexity of a child's syntax increases, phonological development may lag behind. Additionally, Jartun (1992) found that 4-yearold subjects with a history of expressive language delay fell within the normal range syntactically. Intelligibility, however, remained significantly below that of children with normally developing linguistic skills. These findings may suggest that a stronger relationship between intelligibility and linguistic development may exist at younger age levels.

Regression analysis was performed to compare the slopes of the correlations for the four groups of intelligibility. Results indicated that there were no significant differences between the slopes. These results suggest that MLU and PIW do not have a stronger or weaker relationship as intelligibility decreases. Additional research may isolate other variables which differentiate between severity levels of intelligibility. 
CHAPTER V

\section{SUMMARY AND IMPLICATIONS}

\section{Summary}

Previous research has indicated that speech and linguistic variables develop concurrently. When one aspect of speech and linguistic development is delayed, there are typically associated delays in another area as well. This interactive relationship has been studied extensively in the context of phonological and syntactical development, as well as fluency and syntactical development. The relationship between intelligibility and linguistic proficiency has not been studied as extensively.

The purpose of this study was to examine the relationship between varying levels of intelligibility and length and complexity of language in preschool-aged children. Mean length of utterance (MLU) was correlated with the mean percentage of intelligible words (PIW) in a continuous speech sample.

The following questions were addressed:

1. Does a significant positive correlation exist between MLU and percentage of intelligible words in a continuous speech sample?

2. Are there significant differences in the correlations of MLU and percentage of intelligible words between four groups of young children with a range of 
intelligibility levels: mild, mild-moderate, moderatesevere, and severe?

A continuous speech sample was collected from each of the subjects. Children were separated into four groups based on intelligibility ratings of mild, mild-moderate, moderate-severe, and severe. These ratings were based on the percentage of mean intelligible words in a continuous speech sample. Correlations between MLU and PIW were obtained using the Pearson Product Moment Correlation. Regression analysis was used to determine whether a significant difference exists between the correlations for the four groups of intelligibility.

An overall significant positive correlation was found between MLU and PIW when the four groups of subjects were combined. Significant correlations were also found between MLU and PIW for the groups with intelligibility ratings of mild and mild-moderate. No significant correlations were revealed between the two variables for the moderate-severe or severe groups. Regression analysis indicated no significant differences in the correlations for the four groups of intelligibility. This resulted in a failure to reject the null hypothesis that the correlations among the four groups of intelligibility levels will be the same. 
Implications

\section{Research}

Future research is necessary to more thoroughly explore and understand the relationship between intelligibility and linguistic development. The present study raises several questions which could be examined in additional studies. Research may include examining other measures of linguistic development in relation to intelligibility. Length and complexity of language may be analyzed separately to determine the independent effects of each factor. Other measures of linguistic development such as vocabulary or complex sentence development may also show a significant relationship with intelligibility. Additional research may also identify those measures of linguistic development that have a stronger relationship with moderate and severe levels of intelligibility. If such a relationship existed, lower intelligibility levels could serve as an indicator of potential difficulty with specific linguistic skills.

The relationship between intelligibility and cognitive development could be explored as well. Further investigation of a limited encoding capacity may also be warranted. Research could determine the proportion of children who are actually able to increase their linguistic or phonological skills to meet the demands of the message. A negative correlation may suggest such a relationship. The present sample included only 4- and 5-year-old children. 
Additional research with a more stratified age sample may reveal a more or less significant correlation between PIW and MLU.

clinical

The results of this study indicated an overall positive relationship between mean length of utterance and mean intelligible words in a continuous speech sample. These data support the existing research that suggests all delayed aspects of speech and language should be targeted concurrently. If only one aspect of the linguistic system is targeted at a time, maximum benefits from treatment may not be attained. Results of this study also reinforce the validity of assessing a child's linguistic skills if they present with reduced intelligibility. 
References

Amorosa, H., von Benda, U., \& Wagner, E. (1990).

Cognitive variables as predictors of progress in grammar: A longitudinal study of unintelligible children. Folia Phoniatrica, 42, 53-59.

Brown, R. (1973). A first lanquage. Cambridge, MA: Harvard University Press.

Carrow-Woolfolk, E. (1985). Test for auditory comprehension of lanquage-revised. Allen, TX: DLM. Connell, P., \& Myles-zitzer, C. (1982). An analysis of elicited imitation as a language evaluation procedure. Journal of Speech and Hearing Disorders, 47, 390-396.

Gaines, N.D., Runyan, C.M., \& Meyers, S.C. (1991). A comparison of young stutters' fluent versus stuttered utterances on measures of length and complexity. Journal of Speech and Hearing Research, 34, 37-42.

Gordon-Brannan, M. (1993). Speech intelligibility assessment of young children with varying levels of phonological proficiency/deficiency. Unpublished doctoral dissertation, The wichita state University, wichita, KS. Grunwell, P. (1992). Principled decision making in the remediation of children with phonological disability. In $P$. Fletcher \& D. Hall (Eds.), specific speech and language disorders in children: Correlates, characteristics and outcomes (pp. 215-240). San Diego, CA: Singular Publishing Group. 
Hall, N., Yamashita, T.S., \& Aram, D. (1993).

Relationship between language and fluency in children with developmental language disorders. Journal of Speech and Hearing Research, 36, 568-579.

Ham, R.E. (1990). Therapy of stuttering: Preschool through adolescence. Englewood Cliffs, NJ: Prentice-Hall.

Hodson, B.W., \& Paden, E.P. (1991). A phonological approach to remediation: Targeting intelligible speech. (2nd ed.). Austin, TX: Pro-Ed.

Hodson, B.W. (1992). 1-minute measure of homonomy and intelligibility. Unpublished document.

Jartun, R. (1992) - The percentage consonants correct and intelligibility of normal, language delayed, and history of language delayed children. Unpublished master's thesis, Portland State University, Portland, OR.

Lee, L. (1974). Developmental sentence analysis. Evanston, IL: Northwestern University Press.

McLaughlin, S.F., \& Cullinan, W.L. (1989) • Disfluencies, utterance length, and linguistic complexity in nonstuttering children. Journal of Fluency Disorders, 14, $17-36$

Miller, J.F. (1981). Assessing language production in children. Boston, MA: Allyn and Bacon.

Miller, S. (1991) Percentage of phonological process usage in expressive language delayed children. Unpublished master's thesis, Portland State University, Portland, OR. 
Owens, R.E. (1992). Lanquage development: An

introduction (2nd ed.). Columbus, $\mathrm{OH}$ : Merrill Publishing.

Panagos, J.M., \& Prelock, P. (1982). Phonological

constraints on the sentence productions of language-

disordered children. Journal of speech and Hearing

Research, 25, 171-177.

Panagos, J.M., Quine, M.E., \& Klich, R.J. (1979).

syntactic and phonological influences on children's

articulation. Journal of Speech and Hearing Research, 22 ,

841-848.

Paul, R. \& Shriberg, L. (1982). Associations between

phonology and syntax in speech-delayed children. Journal of Speech and Hearing Research, 25, 536-547.

Prelock, P., \& Panagos, J. (1989). The influence of processing mode on the sentence productions of languagedisordered and normal children. Clinical Linguistics and Phonetics, 3, (3), 251-263.

Rescorla, L. (1989). The language development survey: A screening tool for delayed language in toddlers. Journal of Speech and Hearing Disorders, 54, 587-599.

Rylant, C., \& Gammel, S. (1985). The relatives came.

New York: Bradbury Press.

Scarborough, H.S. (1990). Index of productive syntax. Applied Psycholinquistics, 11, 1-22.

Schwartz, R., Leonard, L., Folger, M.K., \& Wilcox, M.J. (1980). Early phonological behavior in normal-speaking and 
language disordered children: Evidence for a synergistic view of linguistic disorders. Journal of Speech and Hearing Disorders, 45, 536-547.

Shriberg, L., \& Kwiatkowski, J. (1980). Natural processes analysis. New York: Wiley and Sons. Shriberg, L., \& Kwiatkowski, J. (1982). Phonological disorders III: A procedure for assessing severity of involvement. Journal of Speech and Hearing Disorders, 47 , 256-270.

Shriberg, L., Kwiatkowski, J., Best, S., Hengst, J., \& Terselic-Weber, B. (1986). Characteristics of children with phonological disorders of unknown origin. Journal of Speech and Hearing Disorders, 51, 140-161.

Weston, A., \& Shriberg, L. (1992). Contextual and linguistic correlates of intelligibility in children with developmental phonological disorders. Journal of Speech and Hearing Research, 35, 1316-1332.

Weiss, C.E., Gordon, M., \& Lillywhite, H. (1987). Clinical management of articulatory and phonologic disorders. Baltimore: Williams and Wilkens. 
Appendix A

Individual subject Data

\begin{tabular}{|c|c|c|c|c|c|c|}
\hline Group & Sub \# & Age & Sex & $\begin{array}{c}\text { TACL-R } \\
\% \text { ile }\end{array}$ & MLU & PIW \\
\hline$I$ & 1 & $4: 11$ & $F$ & 66 & 4.40 & 92.00 \\
\hline$I$ & 2 & $4: 3$ & $\mathbf{M}$ & 79 & 4.72 & 91.50 \\
\hline$I$ & 3 & $4: 11$ & $\mathbf{M}$ & 91 & 9.56 & 95.25 \\
\hline$I$ & 4 & $4: 10$ & $F$ & 98 & 6.38 & 93.50 \\
\hline$I$ & 5 & $4: 5$ & $\mathbf{F}$ & 89 & 4.96 & 96.25 \\
\hline$I$ & 6 & $4: 3$ & $\mathbf{M}$ & 67 & 6.88 & 95.50 \\
\hline$I$ & 7 & $4: 11$ & $\mathrm{~F}$ & 88 & 5.78 & 99.50 \\
\hline$I$ & 8 & $4: 8$ & $\mathrm{~F}$ & 95 & 6.22 & 98.25 \\
\hline$I$ & 9 & $4: 6$ & $F$ & 39 & 4.90 & 87.75 \\
\hline$I$ & 10 & $4: 0$ & $\mathbf{F}$ & 64 & 4.32 & 90.00 \\
\hline$I$ & 11 & $4: 7$ & $F$ & 84 & 5.04 & 91.25 \\
\hline$I$ & 12 & $4: 1$ & $\mathbf{M}$ & 17 & 5.30 & 89.50 \\
\hline$I$ & 17 & $4: 5$ & M & 94 & 5.22 & 88.50 \\
\hline$I$ & 18 & $4: 0$ & $F$ & 17 & 3.96 & 86.25 \\
\hline$I$ & 19 & $5: 5$ & $\mathbf{M}$ & 59 & 6.00 & 93.25 \\
\hline$I$ & 20 & $5: 2$ & $F$ & 61 & 5.52 & 97.50 \\
\hline I & 21 & $5: 6$ & $\mathrm{~F}$ & 73 & 5.78 & 86.00 \\
\hline$I$ & 22 & $5: 5$ & $\mathbf{M}$ & 76 & 4.84 & 93.25 \\
\hline$I$ & 24 & $5: 0$ & $\mathbf{M}$ & 46 & 5.42 & 86.00 \\
\hline$I$ & 27 & $4: 1$ & $\mathbf{M}$ & 57 & 4.42 & 85.75 \\
\hline I & 30 & $4: 8$ & M & 31 & 5.00 & 85.50 \\
\hline I & 45 & $4: 1$ & $\mathbf{M}$ & 50 & 4.60 & 86.00 \\
\hline II & 13 & $4: 11$ & $F$ & 97 & 6.52 & 83.00 \\
\hline II & 14 & $4: 8$ & $\mathrm{M}$ & 11 & 4.20 & 73.00 \\
\hline II & 15 & $4: 2$ & $\mathbf{M}$ & 14 & 3.70 & 71.25 \\
\hline II & 16 & $4: 10$ & $\mathbf{F}$ & 97 & 5.76 & 77.50 \\
\hline
\end{tabular}




\begin{tabular}{|c|c|c|c|c|c|c|}
\hline Group & sub \# & Age & Sex & $\begin{array}{c}\text { TACL-R } \\
\% \text { ile }\end{array}$ & MLU & PIW \\
\hline II & 23 & $4: 0$ & $\mathbf{M}$ & 35 & 5.88 & 81.25 \\
\hline II & 25 & $4: 7$ & $F$ & 85 & 5.44 & 75.50 \\
\hline$I I$ & 26 & $5: 0$ & $\mathbf{M}$ & 57 & 4.80 & 84.50 \\
\hline II & 28 & $5: 0$ & $\mathbf{M}$ & 94 & 4.24 & 78.75 \\
\hline II & 29 & $4: 3$ & $\mathbf{M}$ & 47 & 4.82 & 70.50 \\
\hline II & 31 & $5: 0$ & $\mathbf{M}$ & 76 & 4.56 & 80.00 \\
\hline II & 32 & $4: 9$ & $\mathbf{M}$ & 57 & 5.00 & 70.75 \\
\hline II & 33 & $4: 6$ & $M$ & 62 & 4.66 & 68.75 \\
\hline II & 41 & $4: 2$ & $F$ & 12 & 4.10 & 67.00 \\
\hline II & 42 & $5: 1$ & $F$ & 35 & 3.48 & 69.50 \\
\hline III & 34 & $4: 2$ & $F$ & 38 & 5.28 & 59.25 \\
\hline III & 35 & $4: 4$ & $\mathbf{M}$ & 43 & 4.76 & 61.00 \\
\hline III & 36 & $4: 8$ & $\mathbf{M}$ & 31 & 4.86 & 50.25 \\
\hline III & 38 & $4: 1$ & $F$ & 35 & 2.40 & 55.75 \\
\hline III & 40 & $4: 10$ & $\mathrm{~F}$ & 27 & 4.66 & 50.00 \\
\hline III & 46 & $4: 9$ & M & 29 & 3.74 & 63.50 \\
\hline IV & 37 & $4: 0$ & $\mathbf{M}$ & 41 & 4.52 & 46.00 \\
\hline IV & 39 & $4: 0$ & $\mathbf{M}$ & 37 & 2.72 & 41.75 \\
\hline IV & 43 & $4: 8$ & $\mathrm{~F}$ & 16 & 2.88 & 49.50 \\
\hline IV & 44 & $4: 2$ & $\mathbf{M}$ & 44 & 3.44 & 35.75 \\
\hline IV & 47 & $4: 9$ & $\mathbf{M}$ & 27 & 4.24 & 47.00 \\
\hline IV & 48 & $4: 5$ & $\mathbf{M}$ & 2 & 2.14 & 18.75 \\
\hline
\end{tabular}

Note: Sub \#= subject \#; MLU = mean length of utterance score; PIW = percentage-of-words understood in continuous speech 
Appendix B

Utterance Examples of the Four Intelligibility Groups

Mild Intelligibility:

1. They went in the workshop.

2. They're running towards the car.

3. They're pushing each other into the water.

4. They're all crashing into their house.

5. She's giving some of her meat to the dog.

Mild-Moderate Intelligibility:

1. Look at all of those people.

2. They broked the mailbox.

3. They forgot to close window.

4. They knocked down that.

5. Why they are going down there?

Moderate-Severe Intelligibility:

1. They are eating.

2. That broken

3. Him gonna get a haircut.

4. Go by-bye.

5. She giving him something to eat.

Severe Intelligibility:

1. They leave them new home.

2. Them are happy.

3. Those stickers.

4. Wheel broke.

5. That was a accident. 